\title{
FAKTOR-FAKTOR YANG MEMPENGARUHI MINAT PETANI KELAPA SAWIT RAKYAT BERPARTISIPASI DALAM SERTIFIKASI PRODUK DI KABUPATEN KAMPAR
}

\author{
Rizka Emilia, Sakti Hutabarat, Arifudin \\ Departement of Agribussines, Faculty of Agriculture University of Riau \\ Jl. Binawidya 30, Pekanbaru 28291 \\ E-mail: Rizkaemilia@yahoo.co.id
}

\begin{abstract}
Oil palm product certification consists of the Roundtable of Sustainable Palm Oil (RSPO) and the Indonesian Sustainable Palm Oil (ISPO). RSPO certification is a voluntary certificate that must be met by oil palm mills to sell their products in international market. ISPO is a mandatory certificate that must be comply by grower and miller which operate their bisnis in Indonesia. A number of principles and criteria must be comply by smallholders to obtain RSPO certificate. The objective of this study is to analyse farmer perception and factors that influence smallholder participation in certification in Kampar Regency. The population of this study are scheme smallholders (NES/KKPA) and independent smallholders. This study use Summated Likert scale rating to evaluate farmers' perception and binary logistic regression to assess smallholders participation. The results show that certification is very important while it is important for independent smallholders. Education and land size are factors that influnce scheme smallholders in participating in certification while eduction, land size and job are factors that influence independent smallholders.
\end{abstract}

Keywords: product certification, oil palm, smallholders, perception, participation

\begin{abstract}
Abstrak: Pertumbuhan kesadaran dalam produksi kelapa sawit yang berkelanjutan telah memotivasi kelembagaan internasional untuk mengeluarkan sertifikat kelapa sawit (sertifikat RSPO) sedangkan pemerintah Indonesia mengeluarkan kelapa sawit Indonesia berkelanjutan (ISPO). Sertifikat RSPO merupakan sertifikat sukarela yang harus dipenuhi oleh oleh pabrik kelapa sawit untuk menjual produknya di pasar internasinal. ISPO sertifikat yang wajib dipenuhi oleh pengusaha dan pabrik kelapa sawit yang beroperasi di Indonesia. Beberapa ketentuan dan kriteria wajib dipenuhi oleh petani untuk mendapatkan sertifikat RSPO. Tujuan dari penelitian ini adalah untuk menganalisis persepsi petani tentang pentingnya peran sertifikasi dan faktorfaktor yang mempengaruhi minat petani untuk berpartisipasi dalam sertifikasi produk di Kabupaten Kampar. Populasi yang digunakan untuk penelitian ini adalah petani pola KKPA dan petani swadaya. Penelitian ini menggunakan analisis skala Likert Summated rating untuk mengetahui persepsi petani dan analisis regresi binnary ligistic untuk memahami minat petani dalam partisipasi sertifikasi. Hasil penelitian ini menunjukkan bahwa persepsi petani KKPA terhadap pentingnya peran sertifikasi adalah sangat penting sedangkan persepsi petani swadaya adalah penting. Pendidikan dan luas lahan merupakan faktor yang mempengaruhi minat petani KKPA untuk berpartisipasi dalam sertifikasi sedangkan pendidikan, luas lahan dan pekerjaan merupakan faktor yang mempengaruhi petani swadaya.
\end{abstract}

Kata kunci: sertifikasi produk, RSPO, ISPO, persepsi, partisipasi 


\section{PENDAHULUAN}

Saat ini Indonesia dan Malaysia menguasai $85 \%$ dari pangsa pasar CPO dunia, dimana Indonesia mampu mengekspor $40,34 \%$ dalam bentuk CPO dan 59,66\% dalam bentuk produk olahan CPO sedangkan Malaysia mengekspor $16,38 \%$ dalam bentuk CPO dan $83,62 \%$ dalam bentuk produk olahan CPO (Depperin, 2010). Banyaknya permintaan akan CPO meningkatkan pertumbuhan industri kelapa sawit, khususnya di Indonesia.

Secara umum industri kelapa sawit menunjukkan kinerja ekonomi yang sangat prospektif. Tingkat keuntungan yang menggiurkan mendorong pertumbuhan industri dan perkebunan kelapa sawit yang sangat pesat, menyebabkan kontribusi perkebunan kelapa sawit terhadap perekonomian cukup baik terhadap pengembangan wilayah, Pendapatan Daerah Regional Bruto (PDRB), maupun lapangan kerja (Kadir, 2012). Berkembangnya industri kelapa sawit tidak terlepas dari bagaimana pengelolaan minyak sawit yang berkelanjutan dan lestari.Industri kelapa sawit sering dituding sebagai salah satu penyebab perubahan iklim, pemanasan global, rusaknya lingkungan dan hutan-hutan tropis serta hilangnya keanekaragaman hayati yang ada (Hadad, 2010).Tuntutan dari pasar global terhadap pengolahan perkebunan dan pengelolaan kelapa sawit yang bertanggung jawab dengan memperhatikan aspek lingkungan, sosial, dan ekonomi saat ini menjadi semakin luas dan berdampak terhadap perdagangan luar negeri.

Sertifikasi kelapa sawit merupakan salah satu cara untuk menanggulangi dampak lingkungan, permasalahan sosial, pemanasan global, pemusnahan spesies langka dan dampak lainnya yang ditimbulkan oleh kelapa sawit. Rountable on Sustainable Palm Oil (RSPO)dan Indonesia Sustainable Palm Oil (ISPO) merupakan lembaga sertifikasi kelapa sawit yang akan memberikan standar kualitas produk-produk yang berbahan baku minyak sawit (Darussamin, 2012). Sertifikasi produk kelapa sawit yang disyaratkan oleh kedua lembaga sertifikasi kelapa sawit ini menimbulkan konsekuensi baru, yaitu produk CPO yang diterima di pasar international harus berasal dari produksi yang tersertifikasi kelapa sawit mulai dari produk Tandan Buah Segar
(TBS) sebagai bahan baku hingga pengolahan TBS menjadi CPO dan produk-produk turunan lainnya (Infosawit, 2013).

Pengusaha perkebunan kelapa sawit diharapkan mampu menerapkan sertifikasi produk kelapa sawit yang sudah ditetapkan. Standar yang diterapkan tidak mudah untuk dipenuhi oleh pengelola perkebunan kelapa sawit, terutama perkebunan rakyat. Karakteristik perkebunan rakyat dengan berbagai keterbatasannya menghadapi kendala dalam memenuhi standar tersebut. Bagaimana petani perkebunan rakyat dapat memenuhi persyaratan standarisasi dan faktor-faktor apa saja yang mempengaruhi minat petani kelapa sawit rakyat dalam berpartisipasi terhadap sertifikasi merupakan isu penting yang menjadi fokus penelitian ini. Tujuan penelitian ini adalah untuk mengetahui persepsi petani terhadap pentingnya peran sertifikasi kelapa sawit dan menganalisis faktor-faktor yang mempengaruhi minat petani untuk berpartisipasi dalam sertifikasi kelapa sawit.

\section{METODE PENELITIAN}

\section{Tempat dan Waktu Penelitian}

Penelitian ini dilaksanakan di Desa Bukit Sembilan, Kecamatan Bangkinang, Kabupaten Kampar Provinsi Riau pada bulan Oktober 2013 sampai dengan bulan Mei 2014. Lokasi ini dipilih dengan pertimbangan bahwa usaha perkebunan kelapa sawit merupakan mata pencaharian utama masyarakat dan di daerah ini juga terdapat perusahaan perkebunan kelapa sawit yang dikelola dalam bentuk KKPA bekerja sama dengan KUD induk di Desa Bukit Payung (KUD Sawit Jaya). KUD tersebut miliki tiga belas cabang, dan memilih satu cabang yaitu KUD Bukit Sembilan.

\section{Data dan Sumber Data}

Data yang dibutuhkan dalam penelitianadalah data primer dan data sekunder. Data primer terdiri dari identitas responden, persepsi dan partisipasi. Data sekunder seperti: gambaran umum wilayah penelitian, kependudukan, sarana kesehatan, sarana ekonomi, keragaan perusahaan inti/mitra dan profil KUD Bukit Sembilan. Data primer diperoleh dari wawancara dengan menggunakan kuisioner 
kepada petani KKPA dan swadaya, sedangkan data sekunder diperoleh dari instansi pemerintah terkait seperti: Badan Statistik Provinsi Riau, Dinas Perkebunan Kabupaten Kampar, Koperasi Sawit Jaya, KUD Bukit Sembilandan Kantor dan Desa Bukit Sembilan.

\section{Metoda Pengambilan Sampel}

Penelitian ini dilakukan menggunakan metode survei dengan mengadakan pengamatan langsung ke lapangan. Petani kelapa sawit rakyat dengan pola perkebunan KKPA dan swadaya ditentukan secara purposive samplingdengan menggunakan persamaan Slovin pada tingkat kesalahan 10\% . Dari 353 petani KKPA dipilih sebanyak 78 sebagai sampel. Dari 152 petani swadaya dipilih 61 sampel. Dengan demikian jumlah sampel dalam penelitian ini adalah 139 orang. Responden ditentukan secara purposive yaitu petani yang memiliki tanaman kelapa sawit yang telah berproduksi dan menjadi anggota KUD Bukit Sembilan

\section{Analisis Data}

Persepsi petani terhadap pentingnya sertifikasi kelapa sawit dilihat dengan menggunakan analisis skala likert summated rating (SLR). Skala ini memungkinkan responden untuk mengekspresikan intensitas perasaan mereka. Pertanyaan yang diberikan adalah pertanyaan tertutup.Pilihan dibuat dari intensitas paling rendah sampai intensitas paling tinggi (Akdon, 2005).Untuk mengetahui rentang skala partisipasi petani terhadap sertifikasi kelapa sawit dan pentingnya peran sertifikasi kelapa sawit pada perkebunan kelapa sawit menggunakan rumus sebagai berikut:

RentangSkala $=\frac{\text { Skalatertinggi }- \text { skalaterendah }}{\text { Banyakskala }}-0,01$

Rentang penilaian berkisar sampai 4 yaitu penilaian tertinggi. Rentang skala pada penilaian ini dihitung sebagai berikut :

RentangSkala $=\frac{4-1}{4}-0,01=0,74$

Faktor-faktor yang mempengaruhi minat petani untuk berpartisipasi dalam sertifikasi kelapa sawit dilihat dengan menggunakan alat pengolahan data berupa perhitungan regresi, dengan menggunakanmodel regresi binary logistic dengan modelregresi binary logistic, dengan penyelesaian metode normit (Nawari, 2010).

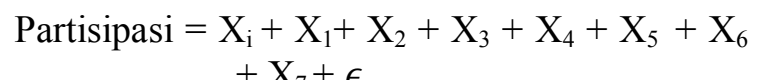

Keterangan :

Partisipasi

: Indikator
penerapanpraktek
pengelolaan terbaik
$(0=$ tidakberpartisipasi
terhadap sertifikasi
kelapa $\quad$ sawit, $1=$
berpartisipasi terhadap
sertifikasi kelapa sawit)
: Usia petani (tahun)
: Lamanya pendidikan
petani (tahun)
Umur $\left(\mathrm{X}_{1}\right) \quad$ : Usia petani (tahun)
Pendidikan $\left(\mathrm{X}_{2}\right)$ : Lamanya pendidikan

Jumlah anak $\left(\mathrm{X}_{3}\right) \quad \begin{gathered}\text { : Berapa jumlah anak } \\ \text { (orang) }\end{gathered}$

Luas $\left(\mathrm{X}_{4}\right) \quad$ : Luas lahan ( ha )

Jenis tanah $\left(\mathrm{X}_{5}\right) \quad$ : Jenis $\operatorname{tanah}(\mathrm{M}=$ mineral, Peat $(\mathrm{P})=$ gambut, Clay $(\mathrm{C})=\quad$ tanah liat, Sand $(\mathrm{S})=$ pasir, $\mathrm{L}=$ loam)

Pekerjaan $\left(\mathrm{X}_{6}\right) \quad$ : Jenis pekerjaan $(0=$ tidak ada pekerjaan lain, $1=$ punya pekerjaan lain)

Keuntungan $\left(\mathrm{X}_{7}\right) \quad$ : Keuntungan tahunan $(0=$ tidak menguntungkan, 1 menguntungkan)

\section{HASIL DAN PEMBAHASAN}

\section{Gambaran Umum Daerah Penelitian}

Kabupaten Kampar memiliki luas wilayah $10.983,46 \mathrm{~km}^{2}$ atau $11,62 \%$ dari luas wilayah Provinsi Riau $\left(94.561,46 \mathrm{~km}^{2}\right)$. Kecamatan Bangkinang merupakan salah satu kecamatan di Kabupaten Kampar yang dulunya bernama Kecamatan Bangkinang Seberang. Luas wilayahnya menurut BPS Kabupaten Kampar (2013) adalah $\pm 130,88 \mathrm{Km}^{2}$ atau $13.088 \mathrm{ha}$, mempunyai tujuh desa dengan pusat pemerintahan berada di Desa Muara Uwai. Salah satu desa di Kecamatan Bangkinang adalah Desa Bukit Sembilan, dengan luas wilayah $8,16 \mathrm{Km}^{2}$ dan jumlah penduduk 1.749 jiwa. 


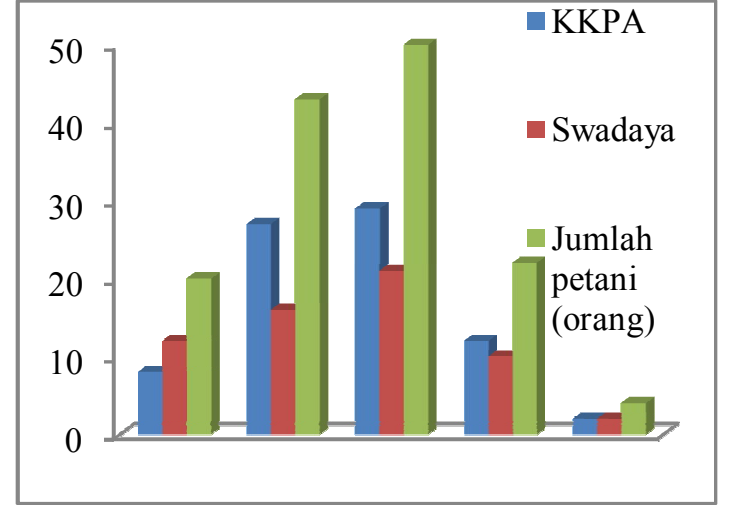

Gambar 1. Umur responden

\section{Identitas Responden}

Responden merupakan petani kelapa sawit KKPA dan swadaya. Petani KKPA merupakan petani yang membudidayakan kelapa sawit dengan bantuan dana dari perusahaan, sedangkan petani swadaya merupakan petani yang membudidayakan kelapa sawit di lahan dan biaya sendiri.Identitas responden diperlukan untuk melihat beberapa hal yang menjadi dasar pertimbangan dalam berpartisipasi terhadap serifikasi. Karakteristik responden dapat dikelompokkan menjadi dua bagian diantaranya yaitu menurut Soekartawi (1993), aspek yang mempengaruhi karakteristik internal responden dalam mengelola usahatani diantaranya adalah umur, tingkat pendidikan, jumlah tanggungan keluarga, lama pengalaman berusahatani, penguasaan lahan yang meliputi luas lahan dan status kepemilikan lahan. Karakteristik eksternal diantaranya adalah intensitas penyuluh, ketepatan saluran penyuluh, jumlah sumber informasi, ketergantungan harga saprodi dan ketersediaan saprodi.

Pada Gambar 1 dapat dilihat umur responden bervariasi dari umur kurang dari 35 tahun sampai75 tahun.Menurut Widyawati (2013), penduduk yang berada pada kisaran umur 15-54 tahun tergolong umur produktif, sedangkan umur 0-14 tahun dan $>54$ tahun tergolong umur tidak produktif.Mayoritas umur petani sekitar 46 hingga 55 tahun, kondisi tersebut dapat disimpulkan bahwa umur petani sawit masih dikatakan produktif.Usia tersebut termasuk usia yang sudah matang dalam berfikir dan mengambil keputusan karena bisa jadi pengalaman dalam berbisnis yang lebih banyak.
Tingkat pendidikan responden bervariasi mulai dari 6 tahun SD, 9 tahun SMP, 12 tahun SMA, bahkan ada yang telah menyelesaikan tingkat sarjana. Untuk mengetahui tingkat pendidikan responden dapat dilihat pada Gambar 2.

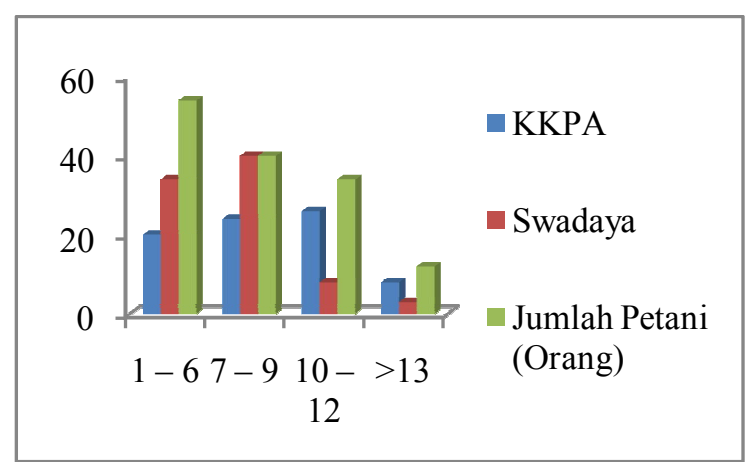

Gambar 2. Pendidikan responden

Pada Gambar 2 dapat dilihat bahwa mayoritas pendidikan formal responden masih rendah. Tingginya rendahnya pendidikan bisa menjadi salah satu faktor terpenting dalam membentuk pola pikir dan proses pengambilan keputusan dalam berusahatani. pendidikan formal yang rendah sebaiknya diiringi dengan pendidikan non formal seperti bimbingan yang diberikan oleh penyuluh perlu dilaksanakan untuk menunjang keberhasilan dalam berusahatani dan meningkatkan pengalaman para petani itu sendiri.

Tanggungan keluarga yang banyak juga menyebabkan pengeluaran yang besar.Jumlah tanggungan keluarga responden dapat dilihat pada Gambar 3.

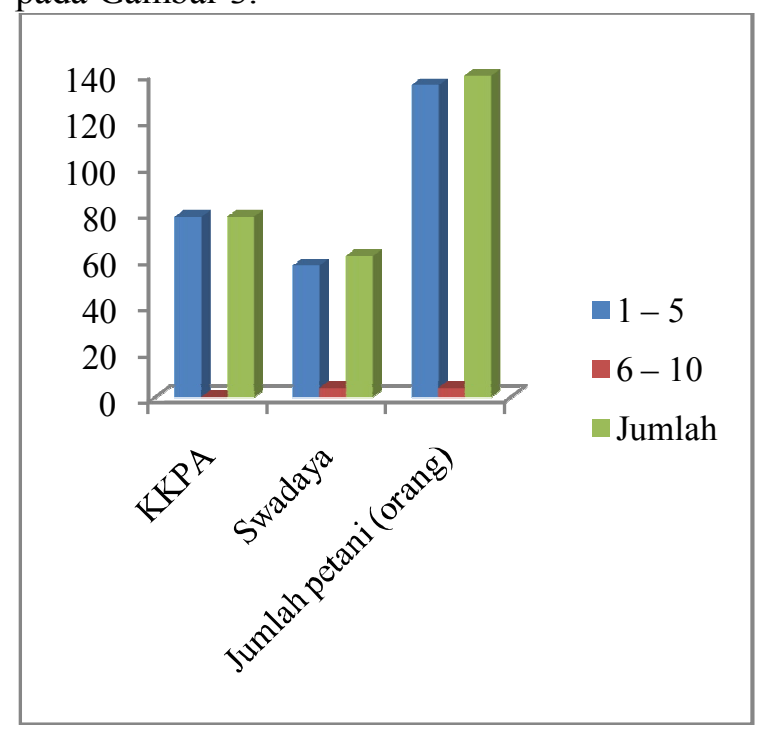

Gambar 3. Jumlah tanggungan responden 
Pada Gambar 3 dapat dilihat bahwa petani KKPA memiliki tanggungan satu sampai lima orang, berbeda dengan petani swadaya. Petani swadaya terdapat empat sampel yang memiliki tanggungan enam sampai sepuluh orang.Tanggungan mempengaruhi pendapatan petani karena semakin banyak tanggungan maka semakin banyak pendapatan petani yang digunakan untuk memenuhi kebutuhan tanggungannya.

\section{Persepsi Petani terhadap Pentingnya Peran Sertifikasi}

Sertifikasi kelapa sawit memiliki prinsip yang harus dilaksanakan oleh pengusaha dan pengelolah perkebunan kelapa sawit. Prinsip sertifikasi terdiri dari:

1. Komitmen terhadap transparansi

2. Mematuhi hukum dan peraturan yang berlaku

3. Komitmen terhadap kelayakan ekonomi dan keuangan jangka panjang
4. Penggunaan praktik perkebunan terbaik dan tepat oleh perkebunan dan pabrik

5. Tanggung jawab lingkungan dan konservasi kekayaan alam dan keanekaragaman hayati

6. Tanggung jawab kepada pekerja, individuindividu dan komunitas dari petani kemitraan dan swadaya

7. Pengembangan perkebunan baru secara bertanggung jawab

8. Komitmen terhadap perbaikan terus menerus pada wilayah-wilayah utama aktivitas

Manfaat sertifikasi kelapa sawit yang menjadi indikator untuk mengukur persepsi petani terhadap pentingnya sertifikasi kelapa sawit. Pengukuran dilakukan dengan menggunakan Skala Likert Summated rating (SLR), yaitu dengan cara menjumlahkan semua skor.

Pada Tabel 1 menunjukkan persepsi petani KKPA terhadap pentingnya sertifikasi kelapa sawit sangat penting dilaksanakan untuk usaha perkebunan kelapa sawit sekarang dan

Tabel 1. Skor Persepsi Tentang Pentingnya Sertifikasi Kelapa Sawit Oleh Petani

\begin{tabular}{|c|c|c|c|c|c|}
\hline No. & Kriteria sertifikasi & KKPA & Keterangan & Swadaya & Keterangan \\
\hline 1. & Identifikasi dampak lingkungan & 299 & $\mathrm{P}$ & 148 & $\mathrm{CP}$ \\
\hline 2. & Identifikasi Spesies langkah & 297 & $\mathrm{P}$ & 204 & $\mathrm{CP}$ \\
\hline 3. & Identifikasi limbah & 293 & $\mathrm{P}$ & 206 & $\mathrm{CP}$ \\
\hline 4. & Identifikasi energy & 296 & $\mathrm{P}$ & 142 & $\mathrm{CP}$ \\
\hline 5. & Tidak menggunakan api & 294 & $\mathrm{P}$ & 140 & $\mathrm{CP}$ \\
\hline 6. & Emisi gas rumah kaca & 295 & $\mathrm{P}$ & 151 & $\mathrm{CP}$ \\
\hline 7. & Menekan biaya & 283 & $\mathrm{P}$ & 141 & $\mathrm{CP}$ \\
\hline 8. & Meningkatkan produktivitas & 295 & $\mathrm{P}$ & 141 & $\mathrm{CP}$ \\
\hline 9. & Ramah lingkungan & 292 & $\mathrm{P}$ & 175 & $\mathrm{CP}$ \\
\hline 10. & Mengurangi masalah sosial & 299 & $\mathrm{P}$ & 164 & $\mathrm{CP}$ \\
\hline 11. & Menjamin keberlanjutan usaha & 292 & $\mathrm{P}$ & 179 & $\mathrm{CP}$ \\
\hline 12. & $\begin{array}{l}\text { Perubahan praktik terbaik } \\
\text { pertanian }\end{array}$ & 297 & $\mathrm{P}$ & 177 & $\mathrm{CP}$ \\
\hline 13. & Menggunakan APD & 294 & $\mathrm{P}$ & 157 & $\mathrm{CP}$ \\
\hline 14. & Meningkatnya biaya produksi & 268 & $\mathrm{P}$ & 159 & $\mathrm{CP}$ \\
\hline 15. & $\begin{array}{l}\text { Hasil TBS ditampung PKS yang } \\
\text { Bersangkutan }\end{array}$ & 281 & $\mathrm{P}$ & 153 & $\mathrm{CP}$ \\
\hline 16. & $\begin{array}{l}\text { Harga yang berbeda dengan non } \\
\text { Sertifikasi kelapa sawit }\end{array}$ & 291 & $\mathrm{P}$ & 159 & $\mathrm{CP}$ \\
\hline & Jumlah & 4.661 & SP & 2.596 & P \\
\hline
\end{tabular}

Sumber: Data Olahan (2014)

Keterangan:

SP : Sangat Penting

$\mathrm{P} \quad$ : Penting

CP : Cukup Penting 
Tabel 2. Analisis Regresi Binary Logistic Petani KKPA

\begin{tabular}{llccclr}
\hline & \multicolumn{1}{c}{ B } & S.E & Df & \multicolumn{1}{c}{ Sig } & \multicolumn{1}{c}{$\operatorname{Exp~(B)~}$} \\
\hline Step 1 $^{\mathrm{a}}$ & X1 & .068 & .060 & 1 & .254 & 1.071 \\
& X2 & .881 & .320 & 1 & $.006^{* * *}$ & 2.414 \\
& X3 & .633 & .511 & 1 & .215 & 1.883 \\
X4 & -4.496 & 2.062 & 1 & $.029^{* *}$ & .011 \\
X5(1) & 2.579 & 29200.722 & 1 & 1.000 & 13.187 \\
X6 & -1.945 & 1.360 & 1 & .153 & .143 \\
X7 & 18.608 & 9717.480 & 1 & .998 & $1.206 \mathrm{E} 8$ \\
& Constant & -26.693 & 9717.480 & 1 & .998 & .000 \\
\hline
\end{tabular}

a. Variable(s) entered on step 1: X1, X2, X3, X4, X5, X6, X7. Keterangan: * signifikan pada $\alpha 10 \%,{ }^{* *}$ signifikan pada $\alpha 5 \%, * * *$ signifikan pada $\alpha 1 \%$

Sumber: Data Olahan SPSS (2014)

dimasa yang akan datang, sedangkan petani swadaya memiliki persepsi sertifikasi kelapa sawit penting dilaksanakan. Perbedaan persepsi petani KKPA dan swadaya disebabkan karena petani KKPA lebih terorganisir dengan lembaga yang sudah ada dan banyak mendapatkan informasi dari penyuluh (perusahaan dan pemerintah) dibandingkan petani swadaya yang mengusahakan kelapa sawit rata-rata dengan sistim turun menurun dan selebihnya memiliki informasi dari media dan penyuluhan (bagi yang mau ikut penyuluhan).

Partisipasi adalah proses tumbuhnya kesadaran terhadap hubungan antara stakeholders yang berbeda dalam masyarakat, yaitu antara kelompok-kelompok sosial dan komunitas dengan pengambil kebijakan dan lembaga-lembaga jasa lain (Syahyuti, 2006). Faktor-faktor yang mempengaruhi minat petani KKPA dan swadaya dalam sertifikasi produk dapat dilihat pada Tabel 2 dan Tabel 3.Berdasarkan Tabel 2 dapat dilihat faktorfaktor yang mempengaruhi minat petani KKPA dalam berpartisipasi terhadap sertifikasi kelapa sawit adalah pendidikan dan luas lahan sedangkan variabel umur, jumlah anak, jenis tanah, pekerjaan dan keuntungan tidak berpengaruh secara signifikan terhadap partisipasi petani dalam sertifikasi kelapa sawit.

$$
\begin{aligned}
\mathrm{Z}= & -26,693+0,068 \mathrm{X}_{1}+0,881 \mathrm{X}_{2}+0,633 \mathrm{X}_{3} \\
& -4,496 \mathrm{X}_{4}+2,479 \mathrm{X}_{5}-1,945 \mathrm{X}_{6}+18,608 \\
& \mathrm{X}_{7}+\epsilon_{\mathrm{i}}
\end{aligned}
$$

$\operatorname{Logit}\left(Z^{* *}\right)=-26,693+0,881 \mathrm{X}_{2}-4,496 \mathrm{X}_{4}+$ $\epsilon$
$Z=-26,693+0,881(9,910)-4,496(1,710)=-$ 25,650

Probabilitas partisipasi sertifikasi kelapa sawit

$\left(\mathrm{P}_{\mathrm{i}}\right)$ adalah $=\frac{1}{1+e^{-(Z * *)}}$

$\mathrm{P}_{\mathrm{i}}=\frac{1}{1+e^{25,650}}=7,250 \times 10^{-12}$

nilai ini menunjukkan probabilitas petani KKPA untuk berpartisipasi sedangkan probabilitas untuk tidak berpartisipasi sebesar 1 $-7,250 \times 10^{-12}=1$.

Nilai Odss Ratio pendidikan petani adalah 2,413 , jika pendidikan petani naik satu tahun maka kemungkinan untuk berpartisipasi naik sebesar 2,413.Pendidikan merupakan lembaga petani dalam mendapatkan ilmu pengetahuan. Pendidikan yang baik akan mempengaruhi partisipasi petani terhadap sertifikasi kelapa sawit. Semakin tinggi pendidikan petani akan semakin besar peluang untuk berpartisipasi, karena petani yang memiliki pengetahuan yang tinggi akan lebih mudah menerima informasi-informasi yang baru. Menurut Scott (1994) pendidikan (pendidikan formal dan pendidikan non formal) dibutuhkan untuk mendukung kemampuan seseorang dalam bekerja, namun hal tersebut tidak mutlak karena adanya keterbatasan sumberdaya yang dimiliki oleh petani, sehingga petani lebih memilih melaksanakan kegiatan usahataninya dengan resiko yang paling rendah berdasarkan pengalamannya sendiri selama berusahatani.

Luas lahan petani memiliki Nilai Odss Ratio0,011 apabila luas lahan petani 
Tabel 3. Analisis Regresi Binary Logistic Petani Swadaya

\begin{tabular}{lllllll}
\hline & \multicolumn{1}{c}{ B } & \multicolumn{1}{c}{ S.E } & Df & \multicolumn{1}{c}{ Sig } & \multicolumn{1}{c}{$\operatorname{Exp~(B)~}$} \\
\hline Step 1 $^{\text {a }}$ & X1 & -.043 & .634 & 1 & .426 & .958 \\
& X2 & .828 & 8.541 & 1 & $.003^{* * *}$ & 2.290 \\
X3 & .198 & .522 & 1 & .470 & 1.218 \\
X4 & .910 & 4.650 & 1 & $.031^{* *}$ & 2.485 \\
X5(1) & 21.375 & 6.242 & 1 & .100 & $1.918 \mathrm{E} 9$ \\
X6 & 3.930 & 6.941 & 1 & $.008^{* * *}$ & 50.929 \\
X7 & -.342 & .079 & 1 & .779 & .710 \\
Constant & -30.355 & .000 & 1 & .999 & .000 \\
\hline
\end{tabular}

Sumber: Data Olahan SPSS (2014)

a. Variable(s) entered on step 1: X1, X2, X3, X4, X5, X6, X7.

Keterangan: * signifikan pada $\alpha 10 \%,{ }^{* *}$ signifikan pada $\alpha 5 \%, * * *$ signifikan pada $\alpha 1 \%$.

bertambah satu ha maka kemungkinan untuk berpartisipasi naik sebesar 0,011. Lahan merupakan tempat petani untuk mengusahakan usaha mereka, baik itu dibidang pertanian maupun industri. Lahan yang dikelola oleh petani KKPA dijadikan tempat usaha kelapa sawit.Luas lahan yang dimiliki oleh petani KKPA sudah ditetapkan secara bersama melalui koperasi.Luas lahan yang dimiliki oleh petani KKPA berbeda dengan petani swadaya, dimana petani swadaya memiliki luas lahan bervariasi.

Faktor-faktor yang mempengaruhi partisipasi petani dengan regresi binary logistic pada petani swadaya dapat dilihat pada tabel 3 .

$Z=-30,355-0,43 X_{1}+0,828 X_{2}+0,198 X_{3}+$ $0,910 \mathrm{X}_{4}+21,371 \mathrm{X}_{5}+3,930 \mathrm{X}_{6}-0,342 \mathrm{X}_{7}+$ $\epsilon$

$\begin{aligned} \operatorname{Logit}\left(\mathrm{Z}^{* *}\right)= & -30,355-0,828 \mathrm{X}_{2}+0,910 \mathrm{X}_{4} \\ & +3,930 \mathrm{X}_{6}+\epsilon\end{aligned}$

$$
Z=-30,355-0,828(7,820)+0,910(2,915)+
$$$$
3,930(0,754)=-31,214
$$

Probabilitas partisipasi sertifikasi kelapa sawit $\left(\mathrm{P}_{\mathrm{i}}\right)$ adalah $=\frac{1}{1+e^{-(Z * *)}}$

$\mathrm{P}_{\mathrm{i}}=\frac{1}{1+e^{31,214}}=2,779 \times 10^{-14}$.

Nilai ini menunjukkan probabilitas petani KKPA untuk berpartisipasi sedangkan probabilitas untuk tidak berpartisipasi sebesar $1-2,779 \times 10^{-14}=1$.

Tabel 3 menunjukkan faktor-faktor yang mempengaruhi partisipasi sesuai hipotesis adalah: pendidikan, luas lahan dan pekerjaan sedangkanvariabel umur, jumlah anak, jenis tanah dan keuntungan tidak berpengaruh secara signifikan terhadap partisipasi petani dalam sertifikasi kelapa sawit. Nilai Odss Ratio untuk pendidikan petani sebesar 2,288 yang artinya jika pendidikan petani naik satu tahun maka kemungkinan untuk berpartisipasi sebesar 2,288. Pendidikan petani swadaya sama dengan pendidikan petani KKPA yang terdiri dari pendidikan formal dan pendidikan non formal. Petani swadaya tidak dibekali pengetahuan seperti petani KKPA, salah satu cara untuk mendapatkan informasi dalam menambah pengetahuan mereka adalah mengikuti pendidikan formal. Pendidikan formal memberikan latihan yang diperlukan kepada orang-orang untuk mendapat pekerjaan yang berketerampilan lebih tinggi. Petani yang memiliki pendidikan tinggi akan mempunyai banyak pengetahuan dan informasi, sehingga akan lebih mudah menerima informasi baru. Pendidikan yang tinggi juga menyebabkan petani swadaya untuk lebih berpartisipasi terhadap sertifikasi kelapa sawit.

Nilai Odss Ratio luas lahan petani adalah 2,484, jika luas lahan petani naik satu ha maka kemungkinan untuk berpartisipasi naik sebesar 2,484. Lahan adalah tempat budidaya kelapa sawit yang merupakan aset untuk dimasa akan datang yang akan diwariskan kepada keluarga mereka. Luas lahan mempengaruhi petani dalam berpartisipasi terhadap sertifikasi kelapa sawit, semakin luas lahan petani semakin besar kemungkinan untuk berpartisipasi demi keberlanjutan usaha mereka dimasa yang akan datang 
Pekerjaan memiliki nilai Odss Ratio 50,306. Petani yang memiliki pekerjaan di luar sebagai petani kelapa sawit akan lebih berpartisipasi terhadap sertifikasi. Petani swadaya cendrung memiliki pekerjaan selain sebagai petani kelapa sawit, hal ini menyebabkan pendapatan petani swadaya tidak dari kelapa sawit saja, tetapi juga dari pendapatan di luar kelapa sawit. Petani yang memiliki pekerjaan selain petani kelapa sawit akan berpartisipasi aktif karena jika kelapa sawit mereka diremajakan, ada penghasilan lain untuk memenuhi kebutuhan mereka.

Petani KKPA dan swadaya dalam berpartisipasi terhadap sertifikasi dipengaruhi oleh faktor-faktor yang sama kecuali pekerjaan. Perbedaan faktor-faktor yang mempengaruhi minat petani dalam berpartisipasi terhadap sertifikasi kelapa sawit disebabkan oleh pola perkebunan yang berbeda.Perkebunan KKPA yang diharapkan menjadi contoh oleh petani swadaya dalam mengusahakan kelapa sawit belum berjalan dengan baik dapat dilihat dari perkebunan yang ada di lapangan.

Petani KKPA dan swadaya Desa Bukit Sembilan, Kecamatan Bangkinang, Kabupaten Kampar mau berpartisipasi dalam informasi baru tentang sertifikasi produk yang berupa RSPO dan ISPO untuk minyak kelapa sawit yang lestari dan berkelanjutan, ini dapat dilihat dari persepsi petani terhadap pentingnya menjaga makhluk hidup, lingkungan dan keutungan yang didapatkan sesuai dengan standar dan kriteria sertifikasi kelapa sawit

\section{KESIMPULAN}

Berdasarkan hasil pembahasan tentang faktorfaktor yang mempengaruhi minat petani untuk berpartisipasi terhadap sertifikasi produk di Kabupaten Kampar yang diuraikan sebelumnya kesimpulan yang didapat adalah:

1. Persepsi petani KKPA tentang manfaat pentingnya sertifikasi kelapa sawit sangat penting diterapkan dengan total skor 4.661 terletak pada skor 4.056-4.992 (kategori sangat penting). Petani swadaya memiliki persepsi tentang sertifikasi kelapa sawit itu penting dengan total nilai 2.596 yang terletak pada rentang $2.184-3.1201$ (kategori penting).

2. Faktor-faktor yang mempengaruhi minat petani dengan pola perkebunanKKPA untuk berpartisipasi dalam sertifikasi kelapa sawit, yang memberikan informasi tentang kelapa sawit yang berkelanjutan dengan sertifikasi kelapa sawit RSPO dan ISPO adalah pendidikan petani dan luas lahan petani, sedangkan faktor - faktor yang mempengaruhi minat petani swadaya dalam berpartisipasi terhadap sertifikasi kelapa sawit (RSPO dan ISPO) dipengaruhi oleh pendidikan, luas lahan dan pekerjaan.

\section{DAFTAR PUSTAKA}

Akdon, dan Hadi Sahlan.2005. Aplikasi Statistika dan Metode Penelitian untuk Administrasi dan Manajemen. Dewa Ruchi. Bandung.

Darussamin, Asril, Murdwi Astuti, Dani Rahadian, Endy, Lgo, Husnawati dan Hikman. 2012. Buku Panduan Penerapan Prinsip dan Kriteria RSPO untuk Petani Kelapa Sawit. RSPO, WWF. Jakarta.

Depperin. 2010. Media Industri.www. Depperin.go.id/2010-01.pdf. Diakses pada 26 Juni 2013.

Hadad, Ismid. 2012. Perubahan Iklim dan Pembangunan Berkelanjutan. Jurnal Prisma, volume 29 no 2, April 2010.

Infosawit. 2013. Isu Lingkungan Ancam Pasar CPO. Www. Infosawit.com.Vol. 2 No. 4 Edisi 7-12 Januari 2013.Diakses pada kamis 23 April 2013.

Kadir, Hanim \& Syapsan.2012. Peran Perkebunan Kelapa Sawit dalam Menyerap Tenaga Kerja di Kabupaten Rokan Hulu.Jurnal Sosial Ekonomi Pembangunan, tahun III no 7, November 2012: 24-32.

Nawari.2010. Analisis Regresi dengan MS Excel 2007 dan SPSS 17. PT Gramedia. Jakarta.

Soekartawi.1993, Agribisnis Teori dan Aplikasinya.Raja Garfindo Persada. Jakarta.

Syahyuti.2006. 30 Konsep Penting dalam Pembangunan Perdesaan dan Pertanian. Bina Rena Pariwara. Jakarta. 
Widyawati, Febriyastuti, Arif Pujiono. 2013. Pengaruh Umur Jumlah Tanggungan Keluarga, Luas Lahan, Pendidikan, Jarak Tempat Tinggal ke Tempat Kerja, dan keuntungan terhadap curah waktu Kerja Wanita di Sektor Pertanian di Desa
Tajuk, Kec. Dipanegoro, Kab. Semarang. Dipanegoro.Journal of economics, tahun 2013 no 1, 2337-3014 